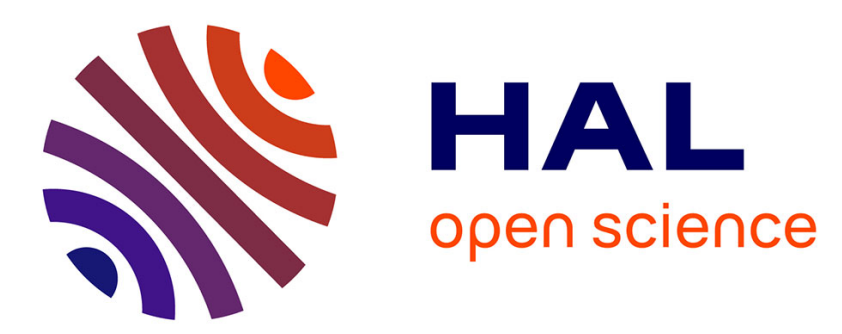

\title{
A NOVEL ELECTRO-OPTIC STORAGE MODE IN SMECTIC A LIQUID CRYSTALS
}

\author{
M. Steers, A. Mircea-Roussel
}

\section{To cite this version:}

M. Steers, A. Mircea-Roussel. A NOVEL ELECTRO-OPTIC STORAGE MODE IN SMECTIC A LIQUID CRYSTALS. Journal de Physique Colloques, 1976, 37 (C3), pp.C3-145-C3-148. 10.1051/jphyscol:1976328 . jpa-00216511

\section{HAL Id: jpa-00216511 https://hal.science/jpa-00216511}

Submitted on 1 Jan 1976

HAL is a multi-disciplinary open access archive for the deposit and dissemination of scientific research documents, whether they are published or not. The documents may come from teaching and research institutions in France or abroad, or from public or private research centers.
L'archive ouverte pluridisciplinaire HAL, est destinée au dépôt et à la diffusion de documents scientifiques de niveau recherche, publiés ou non, émanant des établissements d'enseignement et de recherche français ou étrangers, des laboratoires publics ou privés. 


\title{
A NOVEL ELECTRO-OPTIC STORAGE MODE IN SMECTIC A LIQUID CRYSTALS
}

\author{
M. STEERS and A. MIRCEA-ROUSSEL
}

Laboratoire d'Electronique et de Physique Appliquée 3, avenue Descartes, 94450 Limeil Brevannes, France

Résumé. - Un nouvel effet mémoire dans les smectiques A est décrit et quelques-unes de ses propriétés sont étudiées.

\begin{abstract}
A new electro-optic storage mode in smectic A liquid crystals is described and some of its characteristic features are given.
\end{abstract}

1. Introduction. - Recently, it has been shown that a destabilizing electric or magnetic field operating on monodomain samples of smectic A liquid crystals could induce distortions which, in turn, generate defects $[1,2]$.

Let us consider a planar sample of a smectic $\mathrm{A}$, the dielectric anisotropy $\left(\varepsilon_{a}\right)$ of which is positive, submitted to an increasing electric field. As long as the applied voltage $V$ is less than a threshold value $V_{\text {th }}$, the orientation of the molecules remains unchanged; then, when $V=V_{\text {th }}$, two periodic arrays of defects appear. With still increasing voltage, the following phenomena are successively observed: the regular arrays of lines change into focal conics (Fig. 1) [3]. The size of these focal conics decreases when $V$ increases until a completely scattering texture is observed. Then this texture gradually fades until, for $V=V_{\text {th }}$ the molecules have tilted by an angle of $90^{\circ}$ and the typical conoscopic pattern of an homeotropic sample is observed.

Two storage modes can be obtained :

i) the scattering domains remain stable in time, when the field is removed : first storage mode ;

ii) if the field is cancelled after the sample has

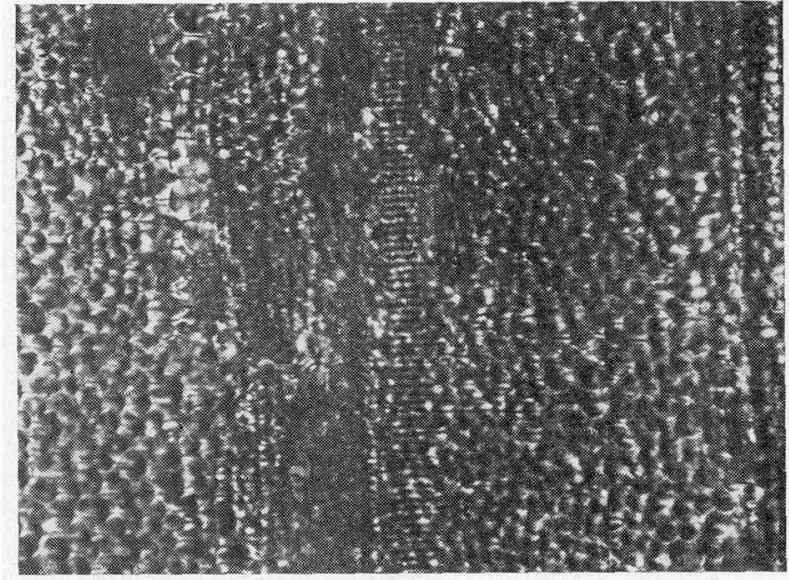

F1G. 1. - Scattering texture obtained by applying a voltage of $25 V_{\text {r.m.s. }}(f=1 \mathrm{kFH})$ on a $22 \mu \mathrm{m}$ thick K 24 sample

$$
\left(T_{\mathrm{SN}}-T=0.5^{\circ} \mathrm{C}\right) \text {. }
$$

become homeotropic, another scattering texture appears, which is stable in time too: this is the second storage mode.

The following diagram summarizes the above described effects :

$\begin{aligned} & \text { planar } \\ & V=0\end{aligned}$ arrays of defects $\rightarrow$ scattering texture
scattering texture (1st storage mode)
$V=0$
$V=0$


In this paper, we present some measurements of the characteristic features of the first storage mode.

2. Experimental details. - The measurements have been performed on two biphenyl compounds : 4 cyano4'-n-octyloxybiphenyl (M 24)

$$
\begin{aligned}
& \text { crystal } \underset{54{ }^{\circ} \mathrm{C}}{\rightleftharpoons} \text { smectic } A \underset{64{ }^{\circ} \mathrm{C}}{\rightleftharpoons} \text { nematic } \underset{80^{\circ} \mathrm{C}}{\rightleftharpoons} \text { isotropic } \\
& \varepsilon_{\mathrm{a}}=8.5 \text { at } 66^{\circ} \mathrm{C}
\end{aligned}
$$

and 4 cyano-4'-n-octylbiphenyl (K24)

$$
\begin{aligned}
& \text { crystal } \underset{21^{\circ} \mathrm{C}}{\rightleftharpoons} \text { smectic } A \underset{32.5^{\circ} \mathrm{C}}{\rightleftharpoons} \text { nematic } \underset{40^{\circ} \mathrm{C}}{\rightleftharpoons} \text { isotropic } \\
& \varepsilon_{\mathrm{a}}=7.5 \text { at } 31^{\circ} \mathrm{C} .
\end{aligned}
$$

The sample, sandwiched between two nesa coated glass plates, separated by $12-290 \mu \mathrm{m}$ Mylar spacers, is placed into an electronically regulated oven, and its temperature is measured with an accuracy of $0.1{ }^{\circ} \mathrm{C}$. The planar anchoring is obtained by evaporating silicon monoxide under oblique incidence. A function generator IEC F34 supplies a sine-shaped voltage pulse the duration of which can be varied; the frequency ranges from 0 to $100 \mathrm{kHz}$.

The sample is observed through a polarizing microscope and its transmission level between parallel polarizers is recorded through a photocell on a storage oscilloscope. Figure 2 gives the block-diagram of the experimental set-up.

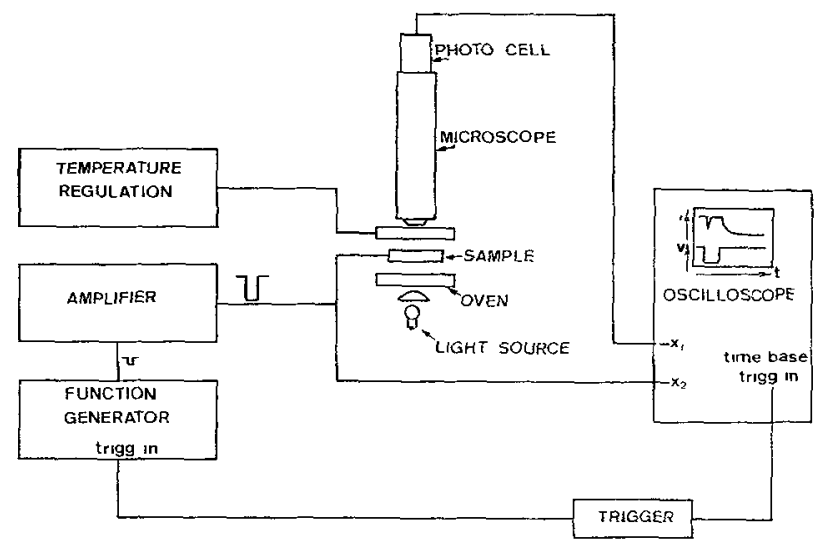

FIG. 2. - Block diagram of the experimental set-up.

3. Experimental results. - We have studied the threshold voltage $V_{\text {th }}$ versus frequency $f$, temperature $T$ and sample thickness in the following ranges : $0<f<100 \mathrm{kHz}, 12 \mu \mathrm{m}<d<75 \mu \mathrm{m}$, $0.2^{\circ} \mathrm{C}<T_{\mathrm{SN}}-T<10^{\circ} \mathrm{C}\left(T_{\mathrm{SN}}\right.$ is the smectic Anematic transition temperature). As shown on figure 3 , $V_{\text {th }}$ is best fitted by the law : $V_{\text {th }}=A d^{1 / 2}\left(T_{\mathrm{SN}}-T\right)^{1 / 3}$; the value of $A$ depends on the studied compound ${ }^{1}{ }^{1}$ ).

(1) The law $V_{\text {th }}=A d^{1 / 2}\left(T_{\mathrm{SN}}-T\right)^{1 / 3}$ has been checked up for thicknesses up to $290 \mu \mathrm{m}$ but for this thickness, our apparatus has restricted us to $T_{\mathrm{SN}}-T<3{ }^{\circ} \mathrm{C}$.

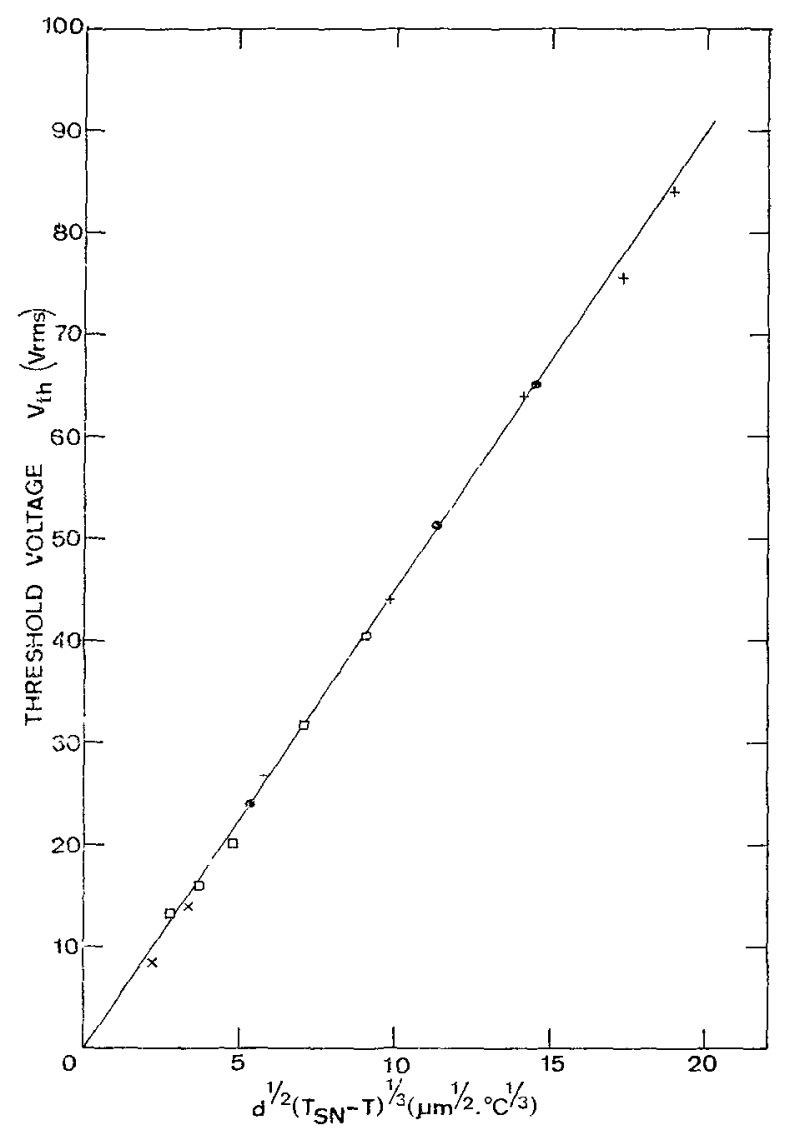

Fig. 3. - Threshold voltage $V_{\mathrm{th}}$ as a function of the thickness $d$ of the sample and the difference $T_{\mathrm{SN}}-T\left(T_{\mathrm{SN}}\right.$ is the smectic A-nematic transition temperature) in $\mathbf{K} 24$ : $+d=75 \mu \mathrm{m}, \quad d=50 \mu \mathrm{m}, \square d=22 \mu \mathrm{m}, \times d=12 \mu \mathrm{m}$, $V_{\mathrm{th}}=A d^{1 / 2}\left(T_{\mathrm{SN}}-T\right)^{1 / 3}$ with $A=4.5 \mathrm{~V} \cdot \mu \mathrm{m}^{-1 / 2}{ }^{\circ} \mathrm{C}^{-1 / 3}$.

Figure 4 displays oscillograms of a $\mathrm{K} 24$ sample (thickness $12 \mu \mathrm{m}, T_{\mathrm{SN}}-T=0.5^{\circ} \mathrm{C}$ ) submitted to a $150 \mathrm{~V}$ pulse of variable length. The upper curve is the photocurrent versus time and the lower curve the voltage applied to the sample versus time. For $\tau=7 \mathrm{~ms}$, the sample experiences the successive states described in the preceding section: initial planar structure (clear), arrays of lines moving into a scattering texture (black) then homeotropic structúre (clear) which relaxes into the second scattering structure (black) when the voltage is removed. For $\tau=3 \mathrm{~ms}$, the structure obtained is only slightly scattering, the highest contrast ratio is then not reached. For $\tau \geqslant 4 \mathrm{~ms}$, the highest contrast ratio is achieved, provided either by the first scattering texture or the second one ; but for $\tau=4 \mathrm{~ms}$ the sample is frozen in the first scattering texture and the revelation time is then the shortest. So a critical pulse length $\tau_{\mathrm{c}}$ exists, for which the highest contrast is achieved in the shortest time. On figure $5 \tau_{\mathrm{c}}$ is plotted as a function of $V / V_{\text {th }}$ for two values of $d$. Typically, for $d=12 \mu \mathrm{m}$, the critical pulse length, which is $60 \mathrm{~ms}$ at $80 \mathrm{~V}\left(V / V_{\text {th }}=5.7\right)$, is reduced down to $7 \mathrm{~ms}$ at $140 \mathrm{~V}\left(V / V_{\mathrm{th}}=10\right)$ for $T_{\mathrm{SN}}-T=0.8^{\circ} \mathrm{C}$. The variation of $\tau_{\mathrm{C}}$ with $V / V_{\mathrm{th}}$ is roughly fitted by a law 

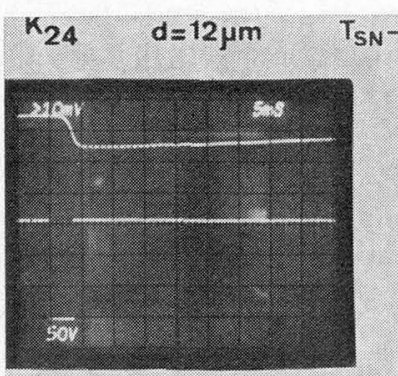

$T=3 \mathrm{~ms}$

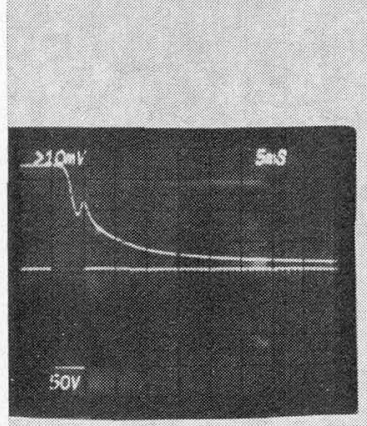

$T=5 \mathrm{~ms}$

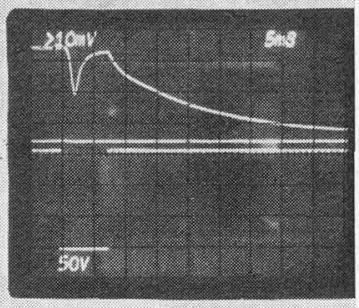

$\mathrm{T}=7 \mathrm{~ms}$

Fig. 4. - Oscillograms of a K 24 sample $(d=12 \mu \mathrm{m}$, $T_{\mathrm{SN}}-T=0.5^{\circ} \mathrm{C}$ ). The upper curve is the light transmitted by the sample between parallel polarizers versus time when it is submitted to a $150 \mathrm{~V}$ pulse of variable duration (lower curve).

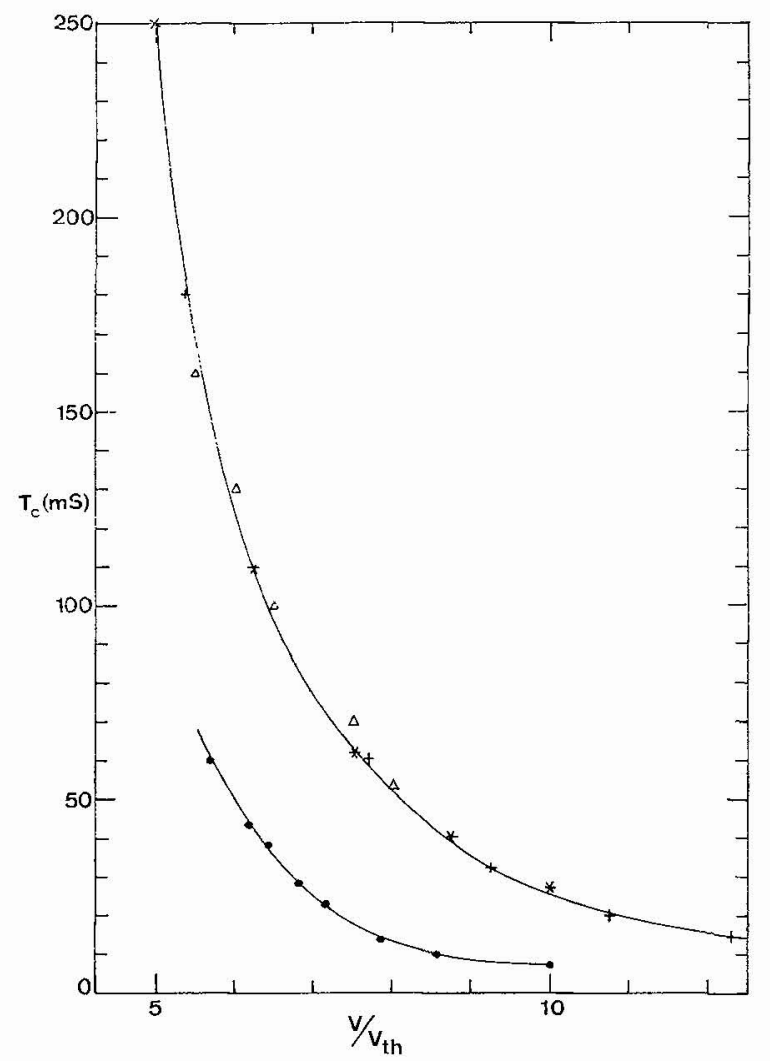

Fig. 5. - Critical pulse length $\tau_{\mathrm{C}}$ versus $V / V_{\text {th }}$ for two $\mathrm{K} 24$ samples : $d=12 \mu \mathrm{m}, T_{\mathrm{SN}}-T=0.8^{\circ} \mathrm{C} ;+d=22 \mu \mathrm{m}$, $T_{\mathrm{SN}}-T=0.25^{\circ} \mathrm{C} ; \quad * d=22 \mu \mathrm{m}, \quad T_{\mathrm{SN}}-T=0.5^{\circ} \mathrm{C}$; $\triangle d=22 \mu \mathrm{m}, T_{\mathrm{SN}}-T=1^{\circ} \mathrm{C}$. The frequency of the applied field is $1 \mathrm{kHz}$.

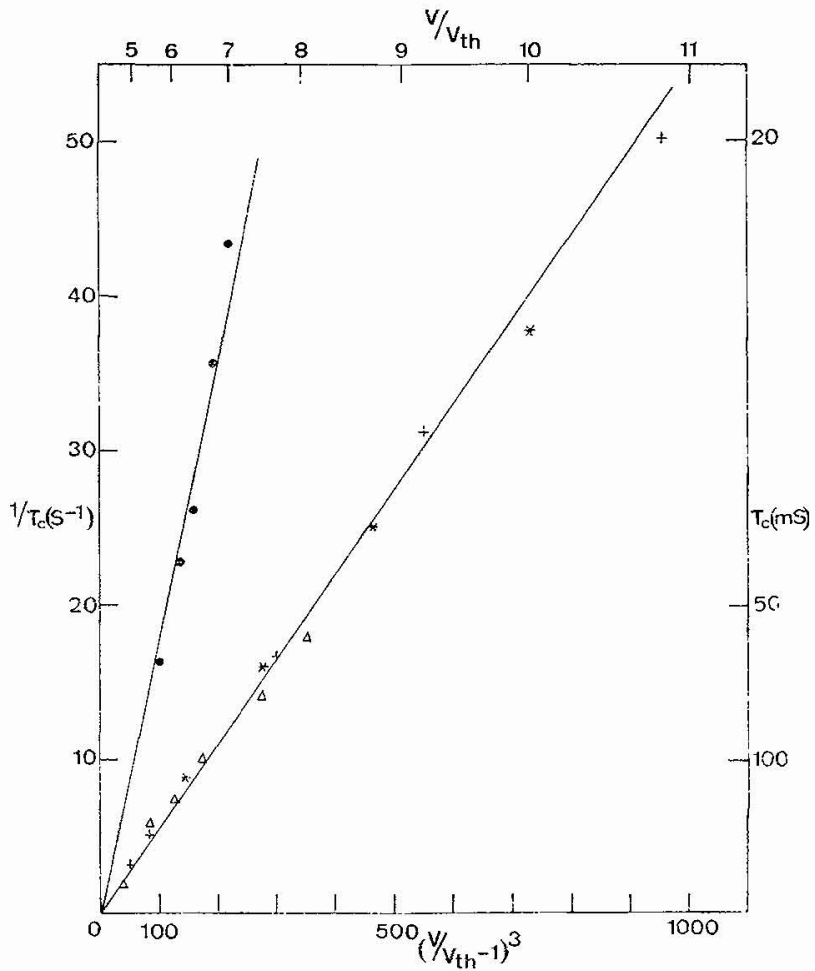

Fig. 6. - Reciprocal of the critical pulse $\tau_{\mathrm{C}}$ versus $\left(V / V_{\mathrm{th}}-1\right)^{3}$ in $\mathrm{K} 24$ samples : $d=12 \mu \mathrm{m}, \quad T_{\mathrm{SN}}-T=0.8^{\circ} \mathrm{C}$; $+d=22 \mu \mathrm{m}, T_{\mathrm{SN}}-T=0.25^{\circ} \mathrm{C} ; * d=22 \mu \mathrm{m}$,

$T_{\mathrm{SN}}-T=0.5^{\circ} \mathrm{C} ; \Delta d=22 \mu \mathrm{m}, \quad T_{\mathrm{SN}}-T=1^{\circ} \mathrm{C}$.

$\left(V / V_{\text {th }}-1\right)^{-3}$ (Fig. 6). At fixed $V / V_{\text {th }}, \tau_{\mathrm{C}}$ increases with sample thickness.

The lifetime of the storage mode depends both on sample thickness and temperature :

$\begin{array}{cccc}T_{\mathrm{SN}}-T^{\circ} \mathrm{C} & 0.25 & 0.5 & 0.75 \\ \text { lifetime }(22 \mu \mathrm{m}) & \overline{20 \mathrm{~s}} & 15 \mathrm{~min} . & >\overline{60} \mathrm{~h} \\ \text { lifetime }(12 \mu \mathrm{m}) & 15 \mathrm{~s} & 7 \mathrm{~min} . & >60 \mathrm{~h}\end{array}$

4. Applications and conclusion. - This storage mode could be used for projection of written slides on a large

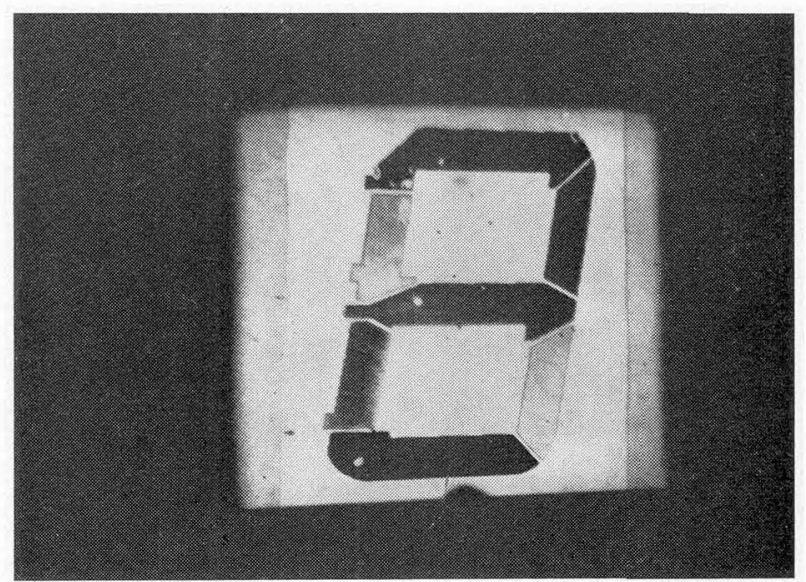

FIG. 7. - Image of a scattering texture, with grey tones, against a planar structure projected on a large screen. K 24 sample $d=20 \mu \mathrm{m}, T_{\mathrm{SN}}-T=0.5^{\circ} \mathrm{C}$. 
screen, the slide being, of course, a sample of smectic $\mathrm{A}$ submitted to an electric field. Two parameters, thus, become important : the resolution and the contrast ratio. The resolution is mainly determined by the size of scattering domains which is imposed by the temperature and the sample thickness : typically at a temperature $0.5^{\circ} \mathrm{C}$ below $T_{\mathrm{SN}}$, in a $22 \mu \mathrm{m}$ thick sample, the resolution is $20 \mu \mathrm{m}$.

The contrast ratio was determined by projecting the image of a cell on a screen and by measuring the intensity with a luxmeter (Fig. 7). The ratio between the light transmitted by the planar structure and the light transmitted by the scattering structure is higher than $40: 1$. Grey tones can be obtained with gradual applied voltages.

Once the scattering texture is obtained, the initial planar alignment can be restored by heating the sample up to the nematic phase, and then cooling it down to the smectic phase at a rate moderate enough to avoid the thermo-optic effect [4].

The authors thank M. Courdille for precious technical assistance.

\section{References}

[1] Goscianski, M., LÉGer, L., Mircea-Roussel, A., J. Physique Lett. 36 (1975) L-313.

[2] Hareng, M., Le Berre, S., Metzger, J. J., Appl. Phys. Lett. 27 (1975) 576.

[3] Léger, L., Rault, I., WrLliams, C. E., to be published in J. Physique Colloq. 37 (1976) C3-89.

[4] Kahn, F. J., Appl. Phys. Lett. 22 (1973) 111. 